\title{
USING REMINDER PROMPTS AND FEEDBACK THROUGH MOBILE DEVICES AND ITS EFFECTS ON ASSIGNMENT RETURN RATES AND ACHIEVEMENT IN MATHEMATICS
}

\author{
Ramzi Nasser ${ }^{1}$, Nassra Al-Banai ${ }^{2}$, Khalid Sahyood ${ }^{3}$ \\ ${ }^{1}$ Higher Education Institute, Supreme Education Council, Doha Qatar \\ ${ }^{2}$ College of Education, Qatar University, Doha Qatar \\ ${ }^{3}$ Qatar Independent Technical Secondary School, Doha Qatar
}

\begin{abstract}
This study determined whether mobile assignment prompts has improved student assignment rate-of-return and achievement in secondary school mathematics. Two groups were matched on achievements level and placed, in an experimental- high frequency mobile assignment prompt; and a second control group; receiving assignment in a traditional manner (in-class handouts). The second phase both groups received the frequent reminders and feedback on the assignment. The control and experimental groups were matched based on equal achievement and hence were randomly assigned either in the control or experimental groups. The findings showed that students in the experimental group who had a longer period of frequent assignment prompts with feedback, scored higher than those in the control group that had increased rate-of-return and higher math achievement scores. We underline the importance of classroom strategies in the improvement of student learning practices by engaging teacher and students with appropriate technologies. The strategies suggested in this study could be implemented in teacher daily school repertoire and could be generalizable to all schools in Qatar.
\end{abstract}

Keywords: mobile devices, school assignment, frequent reminder, feedback, Qatar, mathematics

\section{INTRODUCTION}

Qatar faces challenges in bringing the national mathematics achievement levels to internationally benchmarked outcomes [1]. One of the major factors to students challenges in mathematics is their lack of motivation to complete their out of school assignments. Researchers have documented difficulties students have in completing the assignment because they often lack follow-up by teachers [2], student inaccurate recording of assignment, remembering to take instructions, organizing necessary materials, post assignment strategies as in following through and completing and placing the work in a safe place [3].

One way to deal with issues of assignment is to start developing what is known as advanced learning management in the use of innovative learning technologies. The method allows students to receive information and interact with their teachers to solve problems. It is well known, in a global world, students learning cannot continue to emphasize acquisition of knowledge but also emphasize instrumentalist notions of developing competencies and skills to acquire and generate knowledge. Thus, schools and teachers need to provide educational skills to function in the $21^{\text {st }}$ century [4]. Some of these skills can be developed using innovative learning technologies including information and communication, research, and continuous improvement skills.

Schools now avail the technologies, providing tablets and computers for out of school academic activities. Students also use personal digital assistants, portable media players, Smartphone and handheld game 
consoles which can connect the student to the school, peer and teachers [5]. Many of these tools are mobile devices that are characterized as small, allow students to access, process information at the "palm of their hand," and embark on the use of tools at any time and any place [6]. The most significant aspect of these devices is that youth generally use them for entertainment and could be reached and communicated through them. We know of these devices as mobile travelling with us anywhere imposing no geographical location to learning [7]. The main conjecture of this study; that teachers can use these devices to entice students in doing their out of school assignment.

It was known to the researchers that students have difficulty to keep up with assigned work in schools. Many students would not hand in their assignment and demonstrated failure to translate the theory and knowledge presented in class into a demonstrative learning experience. We conceptualized this study in order to motivate students through advanced organizational techniques and new technologies to advance school assignments. We used what is known as mobile devices, these can be used to engage in the educational activities outside of school. Thus, we used these tools as a way to motivate students to complete assignments in mathematics.

The study included two phases, in the first phase, a control group received assignment in class, an experimental group received the assignment through the mobile devices. This treatment went on for five weeks. Post five weeks, the control and experimental group received the assignment, reminders and feedback through the mobile devices. The feedback included such things as examples and problems solved in class. We compared two groups, control and experimental group post five and ten week's treatments. Thus the research question of this study: "Do "mobile assignments" through reminders compared to reminders with feedback improve student, mathematics academic outcomes whether in completion or achievement?" The main hypothesis of this study is that "students with feedback can increase assignment rate-of-return and mathematics achievement overtime. Thus we see the engagement of these devices as interactive and in real time could provide feedback and reinforcement for positive student learning behaviour. The main objective of this study is to investigate the effects of using smart phones applications to increase completion rates of assignment that could impact student achievement in mathematics.

\section{METHODOLOGY}

The study used an experimental design. The study duration lasted for 10 weeks. Two groups were matched based on a pre-test achievement diagnostic. One group of students was placed in control group and a second group was placed in the experimental group. The control group was administered the assignments through the traditional method and the experimental group was provided frequent reminders for the duration of five weeks. Following five weeks students in the control and experimental group were given frequent reminders with feedback.

All students had mobile devices as Smartphone, those who did not have the devices were lent out for the duration of the study.

Students from two mathematics sections in a secondary school were given a diagnostic test. The test was performed to control for any variations among student achievement level. The achievement score were standardized and students were selected whose scores were between " 1 " standard deviation and " 1 " standard deviation scores. Once students were identified, one group of students was randomly assigned to a control group and one to an experimental group. The first five weeks, the control group was given the assignment in form of handout, the experimental group, was sent the assignment with three reminders daily including weekends (known as the high frequency group). Once the five weeks was over an assessment was performed to assess student mathematics achievement and a number of assignment returns was measured. The subsequent five weeks both groups received the same assignment, frequent reminders and feedback.

An automated text messaging software would prompt the low and high frequency groups through SMS, a social networking systems as well as the school Learning Management System. An assignment calendar reminder was also attached as a messenger to help students know the current assignments, future assignments, and assignment due dates.

\subsection{Sample}

The sample included 40 secondary students. There were 18 students in the traditional control group and 22 in the experimental group. The age of the students was between 17-18 years. Students were in grade 11; the two groups were taught by the same teacher. 


\subsection{Research Site}

The research setting took place in Qatar's Independent Secondary School (public schools) that enrols approximately 450 secondary students. The majority of the student body is Qatari. The schools attendance rate is $85.7 \%$. According to school's timetable, grade 11 has six advanced math lessons per week with 50 minutes per lesson. The total number of students in grade 11 is about 150 students. The school has a friendly atmosphere with high standards for students and staff. The researcher worked closely with the math teacher to develop the structure and interventions i.e., reminders and feedback.

\subsection{Measures and Analysis}

Two main measures included the rate-of-return of assignment and the grades students received on the mathematics assessment. A mean difference between the two groups; traditional and high frequency reminder groups were carried out. Two main analysis were performed in this study. The first analysis involved the rate-of-return on the assignments and scores on the assignment. The second statistical analysis included a Repeated Measure Analysis of Variance and Analysis of Covariance performed to determine the interaction within each group on mathematics achievement and differences between post and pre assessment on mathematics achievement respectively.

\section{FINDINGS}

The first analysis calculated the difference between the two groups in terms of the assignment rate-of-return. The rate-of-return was calculated by adding the number of returns of all students in a group divided by the number of students. The rate-of-return was calculated on a weekly basis. A Repeated Measures Analysis of Variance was performed with rate-of-return as the dependent variable and measured on a weekly basis i.e., repeated over five weeks for the first phase of the study and a second analysis performed for the subsequent five weeks of the study. Table 1 reports the F-ratios with the significant levels. There were no significant differences between the main effects i.e., the first five weeks of the program. There was no significant difference found for linear effects and between treatment effects. In the second part of the experimental design the control and experimental groups received frequent reminders and feedback; there appeared however a significant difference in the main effects i.e. weeks within each group, suggesting that differences within experimental and control groups are significant within each week. There was a linear effect differences exhibited from week 6 to week 10, suggesting an increased linear trend (see Figure 1 and Figure 2). No significant differences appeared between experimental and control group on the rate-of-return.

Table 1.Repeated Measured Analysis over Five Weeks Treatment and 6 to 10 Weeks treatment

\begin{tabular}{l|l|l}
\hline Effects & F-ratio & Sig \\
\hline Main Effect of Weeks (first 5 weeks) & 0.48 & 0.75 \\
\hline Linear Effect (first 5 weeks) & 0.10 & 0.80 \\
\hline Between treatments (first 5 weeks) & 14.88 & 0.16 \\
\hline Main Effect of Weeks (6 to 10 weeks) & 38.64 & 0.002 \\
\hline Linear Effect (6 to 10 weeks) & 1588.6 & 0.016 \\
\hline Between treatments (6 to 10 weeks) & 28.74 & 0.12 \\
\hline
\end{tabular}

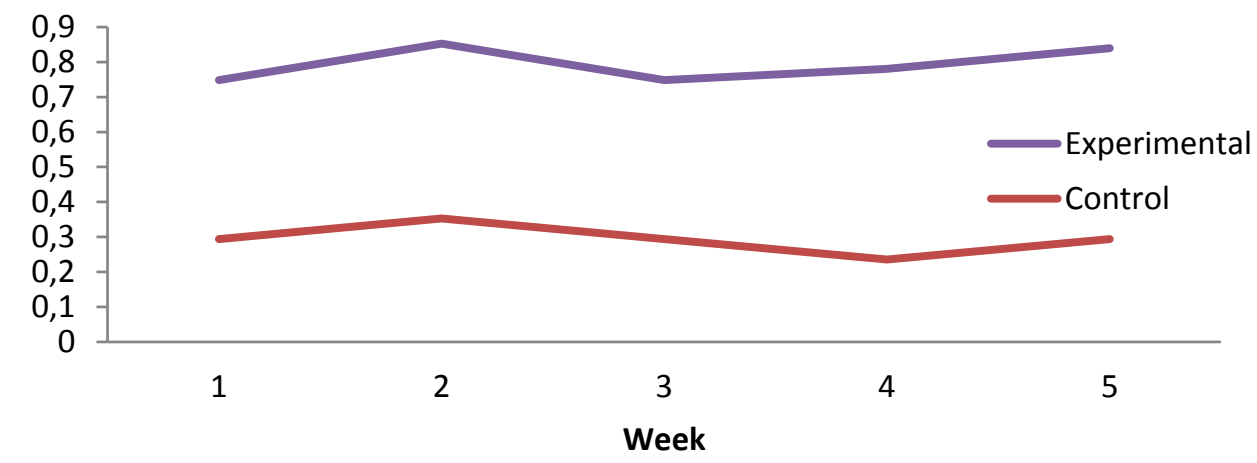

Figure 1.Assignment rate-of-return over the five week period 


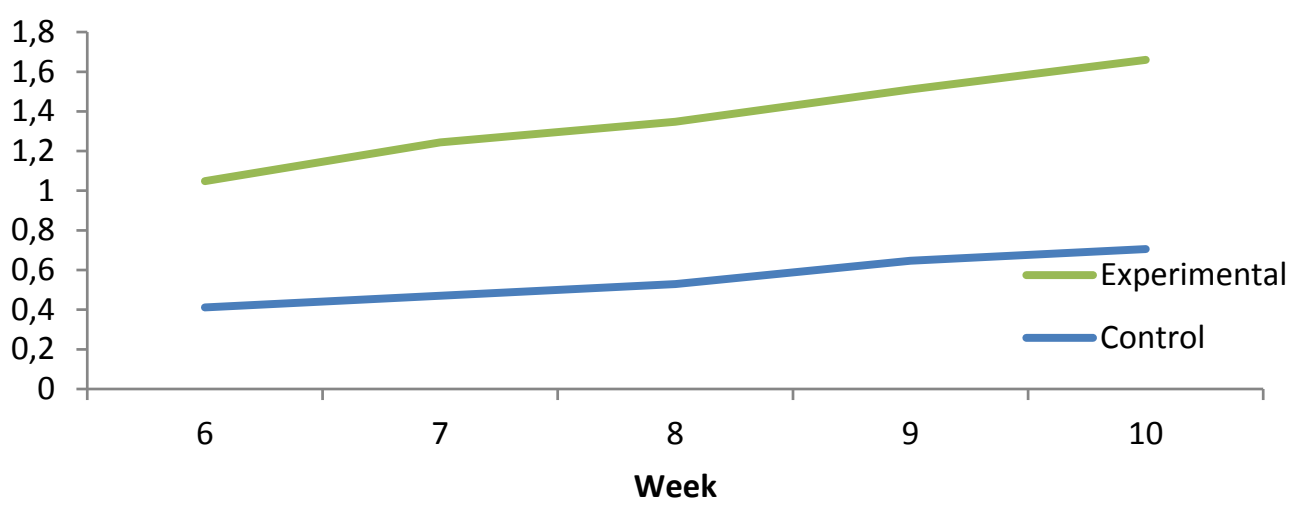

Figure 2.Assignment rate-of-return over the six to ten week period

As mentioned, the first five weeks the control group was administered the assignments through a traditional method whereas; the treatment group was provided frequent reminders through the mobile devices. After the five weeks and first treatment a mean difference test was run $(\mathrm{t}(33)=2.4, \mathrm{p}=0.025)$ comparing means on the mathematics achievement scores. The mean difference was significant with control group $(M=10.88$, $\mathrm{SD}=7.41)$ scoring higher than the experimental group $(\mathrm{M}=6.88, \mathrm{SD}=2.22)$.

Post five-week program, we ran another five weeks treatment, changing the treatment in which the control and experimental groups, both were given frequent assignment reminders with feedback. An analyses of covariance using of two groups- the control and experimental, after 10 weeks of the treatment using mathematics achievement post-test as the dependent variable. The pre-test was given at the end of the fifth week of the study was used as a covariate. The covariate was used to control the differences between mathematics achievement of both groups we ran an Analysis of Covariance using the post-test as the dependent variable. The post-test was given at the end of the $10^{\text {th }}$ week. The main effect showed no significant difference between the control group and experimental $F(1,32)=4.04, p=0.053$. The means on the post-test for the control group $(M=26.75, S D=6.23$ and experimental $(M=31.74 . S D=10.97)$ were not significantly different suggesting that feedback has eliminated the difference due to the frequent reminders and feedback.

\section{CONCLUSION AND IMPLICATIONS}

There are many advantages to the use of mobile devices among teachers and university faculty. These devices and applications can help teachers to manage, organize lesson plans and assignments. Many of these devices are equipped with $3 \mathrm{G} / 4 \mathrm{G}$, touch screen, multimedia software and Apps carried by youth, generally replacing notebooks and pens and have similar functionalities as they take important notes, reading and receiving assignments [8]. The ability for these devices to be mobile has offered new teaching and learning possibilities for teachers and students [9].

In this study we attempted to explore how an assignment structure, regiment and type; can improve through mobile devices to see how students engage in completing and achieve in mathematics The Repeated Measures Analysis of Variance for the first five weeks showed no rate-of-return within difference along the 5 weeks. However along the 6 to 10 weeks, the within rate-of-return shows significant differences. Examining the trends (see figure 1 and Figure 2), over the first five weeks the control group i.e., traditional rate-of-return did not progress linearly as there were ups and downs rates-of-return. While for both the control and experimental groups the linear effect of the rate-of- return in the second part of the study (i.e., form 6 to 10 weeks) showed a progressive positive and linear trend for both groups which received frequent reminders and feedback. While the treatment from 6 to 10 weeks, no significant differences appeared between the two groups: control and experimental on the rate-of-return.

The most interesting findings is the difference between the first treatment in which the control group was given assignment in a traditional way and those in the experimental group received frequent reminder through mobile devices. There was significant difference on achievement level with higher means for the control group. In the second treatment (6 to 10 weeks) when both groups received the same treatment and controlling for the difference in achievement prior to the second treatment the difference between the control and experimental group diminished, suggesting that feedback is a significant component to assignments completion and subsequently achievement. In the second phase of the study, a general trend appears to 
show a general and increased rate-of-return among the two groups that trend showed an increased and positive trend suggesting achievement score improvement due to the feedback system.

The conclusive result suggests that although students in the control group which received the assignment in the first five weeks through a traditional approach showed higher achievement results than the experimental group. Changing the treatment in the $6^{\text {th }}$ week through the $10^{\text {th }}$ by providing frequent reminders and feedback the treatment group achievement scores increased significantly outperforming the control group, thus suggesting reminders and feedback increased students motivational goals to complete and achieve on mathematics.

While in this study we thought to address student outcomes using mobile devices we would see that in any future research and follow-up study, Apps with assignment feedback- regular prompt should avail a richer advanced organizations and intensive and rich experience for students. The feedback to the assignment will include solutions to previous assignments and most common mistakes.

Further note, this study was carried out in Qatar, results of students on mathematics and science, international assessments outcomes have been reported to be as one of the lowest in the world based on the Program for International Student Assessment (Baldi, Jin, Skemer, Green \& Herget, [9]). This raises questions about the Qatari reform, the quality of education in Qatari schools and the role of mobile devices and mobile learning to improve the educational processes.

\section{ACKNOWLEDGEMENTS}

This publication was made possible by UREP grant \# UREP 13-097-5-025 from the Qatar national research fund (a member of Qatar foundation). The statements made herein are solely the responsibility of the author(s)."

\section{REFERENCE LIST}

Brewer, D., Augustine, C., Zellman, G., Ryan, G., Goldman, C., Stasz, C., \& Constant, L. (2007). Education for a new era: Design and implementation K-12 Education reform in Qatar. Pittsburgh, PA: Rand Corporation.

Salend, S. J., \& Gajria, M. (1995). Increasing the assignment completion rates of students with mild disabilities. Remedial and Special Education, Vol. 16, No. 5, 271-279.

Bryan, T., Burstein, K., \& Bryan, J. (2001). Students with learning disabilities: Assignment problems and promising practices. Educational Psychologist, Vol. 36, p.167-180.

Silva, A., Henriques, E. \& Carvalho, A. (2009). Creativity enhancement in a product development course through entrepreneurship learning and intellectual property awareness. European Journal of Engineering Education, Vol. Vol. 34, No. 1, p. 63-75.

Kukulska-Hulme, A. (2007). Mobile usability in educational contexts: What have we learnt? International Review of Research in Open and Distance Learning, Vol. 8, No.2.

Ching, D., Shuler, C., Lewis, A., \& Levine, M. H. (2009). Harnessing the potential of mobile technologies for children and learning. In A. Druin (Ed.), Mobile technology for children: Designing for interaction and learning, (pp.23-42). Amsterdam: Morgan Kaufmann Publishers.

Jonassen, D. H., Carr, C., \& Yueh, H. P., (1998, March). Computers as mind tools for engaging learners in critical thinking, TechTrends, Vol. 43, No. 2, 24-32.

Timmermann, P. (2010) Is my iPad in my backpack? published by Journal of Digital research \& publishing. Retrieved on August 13, 2013 http://www.artichokewebdesign.com/ARIN6912/PDFs/Pilar_Timmerman_Digital_Education.pdf

Baldi, S., Jin, Y., Skemer, M., Green, P.J., \& Herget, D. (2007). Highlights From PISA 2006: Performance of U.S. 15-Year-Old Students in Science and Mathematics Literacy in an International Context (NCES 2008-016). National Center for Education Statistics, Institute of Education Sciences, U.S. Department of Education. Washington, DC. 